\title{
Credit Subsidy Policy and the Moral Hazard of Loan Waivers in the Non-Traded Agriculture Sector in Presence of Credit Market Dualism: A Three- Sector General Equilibrium Model
}

\author{
Sushobhan Mahata*1 and Ranjanendra Narayan Nag ${ }^{2}$ \\ ${ }^{1}$ Department of Economics, University of Calcutta, Kolkata, India \\ ${ }^{2}$ Department of Economics, St. Xavier's College (Autonomous), Kolkata, India \\ *Corresponding author: sushobhanmahata@gmail.com
}

\begin{abstract}
The paper is an attempt to unveil the growth-development tradeoff in the Indian agriculture sector in light of some selected recent policy measures in presence of dualism in both agriculture sector and credit market. Segmentation of the agriculture sector is addressed as traded export agriculture and non-traded agriculture sector. The dualism in the credit market is the coexistence of the formal and informal credit market. In this paper, we construct a three-sector general equilibrium model which may apply to a large class of emerging market economies. The results of the paper reflect contradictions of an emerging economy which is essentially hybrid economics in which capitalist nucleus has a conditional-conditioning relationship with an archaic structure.

JEL Classification: Q14, D58
\end{abstract}

Keywords: Credit market, Agriculture, Development

Globalization has impacted the world economy through various channels that burdening developing economies with loads of liberalization policy measures. These combined policies of LPG marked a distinct line between growth and development. But in a country like India, where the agriculture and the allied sector continues to share a large chunk in employment share, liberalization had invited more criticism than buttering such policies. Our paper will be centered on the circumvented dimensions related to the agriculture sector and questions whether policies aimed at the growth of the agriculture sector output in GDP can escalate development? In this regard, a few facts are pertinent to our analysis. The exportable agricultural commodity has a share of $12.55 \%$ in the total national export of India in the year 2015-16. In agricultural production credit (both formal and informal) plays an important role besides the use of land and labour. The major channels through

${ }^{1}$ Agricultural Statistics at a Glance 2016, page $=300$. which formal credit flows are Public Sector Banks (PSBs), Private Sector Banks, Cooperative Banks and Regional Rural Banks (RRBs). The volume of institutional credit flow in the agricultural sector in India had increased overtime that stands to ₹ $877527 \mathrm{cr}$ in the year 2015-16. The hidden fact is that the formal credit growth rate had dropped significantly in the post-NDA regime (post-2014) ${ }^{2}$. More than $50 \%$ of this formal credit is availed by the small and marginal farmers ${ }^{3}$ (although, sharp fall had been recorded in the Coverage of Small and Marginal Farmers (SMF) in Agriculture Ground level credit (GLC) flow in the last 3 years from $62.7 \%$ in $2013-14$ to $60.1 \%$ in $2017-18^{4}$ ). Still, $40 \%$ of the funds of farmers still come from informal sources (local moneylenders accounted for almost 26\% share of total agricultural credit) ${ }^{5}$.The Government of India modified the Interest Subvention Scheme

\footnotetext{
${ }^{2}$ Agricultural Statistics at a Glance 2016, page $=369$.

${ }^{3}$ Agricultural Statistics at a Glance 2016 page $=407$.

${ }^{4}$ Economic Survey 2017-18, Vol.-II, page $=114$.

${ }^{5}$ Economic Survey 2015-16, Vol.-II, page $=110$.
} 
(ISS) ${ }^{6}$ in the year 2017-18 which will help farmers to avail of short-term crop loans up to ₹ 3 lakh payable within one year at only $4 \%$ interest rate per annum. The attitude of the Government seems to be agriculture friendly in face of Elections; however, a proper evaluation of such policies is imperative to assess the effectiveness of its targeted achievements.

Given this backdrop the present paper attempts to analyze the engagement of some selected populist policy measures mainly, credit subsidy reform and agriculture loan waiver that are directed towards achieving economic growth, with the performance in the agriculture sector (traded and non-traded), manufacturing sector, income inequality and few other related measures of development in presence of imperfection in the credit market. There are enormous pieces of literatures that modelled the credit market interlinkage in the agriculture sector as a partial equilibrium exercise, however there exist dearth of any General Equilibrium (GE) analysis pertaining to the linkage between the working of the credit market and its overall developmental implication. We consider a few related works that are relevant for our purpose. The seminal work of Gupta and Chaudhuri (1996) explored the effect of corruption that interrupts the working of the formal and informal credit market in the agriculture sector under two possibilities of linkage that is when either kind of credit is perfect substitute or complements. Extending in a similar line, Chaudhuri (1996) analyzed credit-product interlinkage under agriculture price uncertainty using a game theoretic approach. Chaudhuri (2001) maintained the baseline of credit market interlinkage, but introduced the existence of a vertical interlinkage between formal and informal credit market, in other words, it assumed that informal lender act as an intermediary between formal sector lender and farmers (final borrowers) thus influencing the informal interest rate that is shown to be an inverse function of formal interest rate. Chaudhuri and Dastidar (2011) introduced information asymmetry that is possessed by the informal moneylenders, which provided a condition for the collusion of all informal lenders and thus breaking the baseline concept of vertical interlinkage between formal-informal credit markets. Chaudhuri (2002) added another line to the existing junction of credit market analysis

${ }^{6}$ Economic Survey 2017-18, Vol.-II, page $=115$ by incorporating credit-labour interlinkage with the existence of credit-product interlinkage. The above mentioned literatures however despite their extensive depth in analyzing the credit market averted from consideration of the risk of lending that is a crucial feature of any credit market. This missing link had been explored by Basu (1997) that formalized several models of credit market by incorporating risk of lending using the Lender's risk hypothesis. Unlike the above mentioned partial equilibrium analysis, the work of Banerjee and Nag (2015) is imperative to mention as an exception that uses a GE framework to analyze liberalization policies in presence of credit market interlinkage and its effect on income inequality and overall growth rate of economy which are otherwise not possible to capture in a partial equilibrium framework.

The present paper attempts to address the impact of reform policies in a three sector-four factor General Equilibrium structure complemented by a microfoundation to endogenize the supply function of informal credit and to explore formal-informal credit market linkage effect with developmental indicators. Our paper is a straight departure from Banerjee and Nag (2015) in several respects. First, unlike the assumption of substitutability between formal and informal credit as in Banerjee and Nag (2015), we assume that either type of credit is complement to each other and used in fixed proportion. The reason behind such a complementary relationship between formal and informal credit can be found in Gupta and Chaudhuri (1996) ${ }^{7}$. Second, our paper highlights the presence of the non-traded agriculture sector which is superseded in Banerjee and Nag (2015) ${ }^{8}$. Lastly, we incorporate the missing link of the risk of loan default in lending as in Basu (1997) but in a different fashion as moneylender's utility maximizing behaviour.

The comparative statics performed in this paper are as follows. We analyze the effects of financial reform in terms of a uniform rise in institutional credit subsidy rate for crop loans, targeted credit

\footnotetext{
${ }^{7}$ Farmers usually resort to formal borrowings to finance large costs or fixed cost, whereas informal borrowings are taken to meet petty seasonal expenses such as labour cost at the beginning of sowing season or at the end of harvest. Informal loans are also taken to meet self-consumption needs.

${ }^{8}$ The role of non-traded sector in any developing economy can be found mentioned in Achcharya and Marjit (2002), Marjit, Kar and Achcharya (2007).
} 
subsidy to the small non-traded agriculture, and moral hazard of farmers' loan waiver policy in terms of an increase in the risk of the loan default rate. The effect of these policy consequences is shown for some development indices such as wage inequality, Gini Index, aggregate workers welfare index (using Sen (1974) index) and credit market exploitation index.

The organization of the paper is as follows. In section 2, we set up the basic model. In its subsection 2.1, we discuss the working of the informal credit market and derive the informal credit supply function as a partial equilibrium exercise. In subsection 2.2, we set up the General Equilibrium economy and discuss its properties. In sub-section 2.3, we discuss some measure of development index and mould them to fit our assumed stylized small open economy. In section 3, we carry out a couple of comparative static exercises pertaining to our analysis of some recent policies pertaining to the agriculture sector. Section 4 concludes the paper.

\section{The Model}

In this section, we construct a three sector-four factor GE model that is motivated by the pioneer works of Jones (1965) and Jones (1971). The brief story is as follows. This is a small open developing economy with dualistic structure in Lewisian sense that is one rural sector and one urban sector. The urban region consists of the import manufacturing sector (sector $M$ ), whereas the rural region is shared by export intensive agriculture sector (sector $X$ ) and non-traded agriculture sector (sector Y). All three sectors use formal credit and informal credit. Skilled labour is specific to the urban region and unskilled labour is mobile only within the rural region. We assume that production structure is a fixed coefficient type, i.e. labour, formal capital and informal capital are used in exogenously determined fixed proportion. All factors earn their competitive return and there exist no unemployment of any factor. Output market is also perfectly competitive, technology is CRS and hence zero profit condition holds. Prices of the traded sector (sector $M$ and sector $\mathrm{X}$ ) are determined in the international market and are exogenous to the domestic economy. Price of the non-traded agriculture sector is domestically determined by forces of demand and supply. The demand for agriculture sector is generated from all the three sectors and we assume that all workers in the economy spend a fixed and uniform fraction of their aggregate income. Formal credit is subsidized in the rural region and its supply is institutionally determined ${ }^{9}$. However, we derive informal credit supply to be a positive function of informal interest rate and a negative function of the probability of loan default. This completes the general description of the stylized economy.

\section{The Moneylender's Tradeoff and the Informal Credit Supply Function}

We consider an informal moneylender who maximizes his utility and the utility is assumed to be a positive function of his expected income (T) and risk-free investment opportunities $(\mathrm{N})^{10}$. The utility function is given by

$$
U=f(T, N), U_{k}>0 \text { for } k=T, N
$$

The utility function is assumed to be strictly quasiconcave and preferences are assumed to be convex, with all other standard properties satisfied. The expected income of the moneylender is given by,

$$
T=(1+\bar{r}) N+(1+i)\left(1-P_{r}\right) I
$$

where, $P_{r} \in[0,1]$

Where $P_{r}$ is the probability of loan default by the borrowers (or, the average loan default), then $1-P_{r}$ is the average rate of repayment by the borrowers. $I$ is the amount of informal lending that is given by,

$$
I=\bar{W}-N
$$

Substituting Eq. (3) into Eq. (2), we get

$$
T=\bar{r} N+(1+i)\left(1-P_{r}\right)(\bar{W}-N)
$$

The equation obtained in (2.1) is amenable to an easy interpretation as follows. It states that moneylender's total expected income is composed of fixed initial wealth $(r N)$ and net income earned from

\footnotetext{
${ }^{9}$ Credit subsidy is enjoyed by the export agriculture sector and non-traded agriculture sector. However, such credit is used by all the three sectors that include the manufacturing sector. To maintain our specificity of analysis, the manufacturing sector is devoid of any kind credit subsidy. Even if the urban sector is provided subsidized credit, the rate of subsidy will differ across rural and urban region.

${ }^{10}$ The risk-free investment opportunities are those investments that are safe such as bank savings (fixed deposits) and involve no uncertainty on its return. These are opposite to risk associated investment such as informal lending as in the present case.
} 
informal lending at given informal interest rate (i). Equation (2.1) can be thus viewed as moneylender's budget constraint. The informal moneylender maximizes Eq. (1) subject to his constraint in Eq. (2.1). The two choice variables involved in the optimization process are $T$ and $N$. Once the optimal value of $T^{*}$ and $N^{*}$ is obtained, we get the supply of informal lending I from Eq. (3). Thus from the entire optimization exercise, we get the informal credit supply function as, ${ }^{11}$

$$
I=I\left(\begin{array}{ccc}
i & \bar{r} & P_{r} \\
(+) & (-)(-)
\end{array}\right)
$$

Eq. (4) shows that informal credit supply is positively related to informal interest rate, and negatively related to formal interest rate and the probability of loan default.

\section{The General Equilibrium Structure}

The following symbols are used in the model.

$$
\begin{aligned}
& a_{k j}=\text { input (k) to output (j) ratio } \gamma=\text { credit subsidy rate } \\
& W_{S}=\text { skilled labour wage rate } \quad \bar{S}=\text { skilled labour endowment } \\
& W=\text { unskilled wage rate } \quad \lambda_{k j}=\mathrm{k}^{\text {th }} \text { factor share in } \mathrm{j}^{\text {th }} \text { sector } \\
& \text { outptut } \\
& \bar{r}=\text { administered formal interest } \bar{L}=\text { unskilled labour endowment } \\
& \text { rate } \\
& i=\text { interest rate on informal } \\
& \text { credit } \\
& P_{M}{ }^{*}=\text { world price of import } \\
& \text { competing good } \\
& I(\cdot)=\text { informal credit supply } \\
& M, X, Y=\text { sectoral outputs }
\end{aligned}
$$

The production structure of the three sectors are described by the following equations,

$$
\begin{aligned}
& M=\min \left(\frac{S}{a_{S M}}, \frac{F}{a_{F M}}, \frac{I}{a_{I M}}\right) \\
& X=\min \left(\frac{L}{a_{L X}}, \frac{F}{a_{F X}}, \frac{I}{a_{I X}}\right) \\
& Y=\min \left(\frac{L}{a_{L Y}}, \frac{F}{a_{F Y}}, \frac{I}{a_{I Y}}\right)
\end{aligned}
$$

Using the equations in Eq.(5) and given factor

${ }^{1}$ See Appendix (A) for detailed optimization process and derivation of informal credit supply function. returns and output level and prices we get zero profit conditions for each sector in partial equilibrium and aggregating them in general equilibrium we get the following set of equations.

$$
\begin{aligned}
& a_{S M} W_{S}+a_{F M} \bar{r}+a_{I M} i=P_{M}{ }^{*} \\
& a_{L X} W+a_{F X}\left(1-\gamma_{1}\right) \bar{r}+a_{I X} i=P_{X}^{*} \\
& a_{L Y} W+a_{F Y}\left(1-\gamma_{2}\right) \bar{r}+a_{I Y} i=P_{Y} \\
& a_{S M} M=S \\
& a_{L X} X+a_{L Y} Y=L \\
& a_{F M} M+a_{F X} X+a_{F Y} Y=F+K_{F} \\
& a_{I M} M+a_{I X} X+a_{I Y} Y=I\left(i, P_{,} r\right) \\
& \alpha(W, S+W L)=P_{Y} Y, \text { where } 0<\alpha<1
\end{aligned}
$$

$$
\begin{gathered}
\frac{\theta_{F X}}{\theta_{L X}}>\frac{\theta_{F Y}}{\theta_{L Y}} \\
\frac{\theta_{L X}}{\theta_{I X}}>\frac{\theta_{L Y}}{\theta_{I Y}}
\end{gathered}
$$

Equations (6)-(8) gives the three zero profit conditions. Equations (9)-(12) give the full employment conditions of all factors. Equation (13) gives the demand-supply for good Y. In other words, Eq. (13) states that $\alpha$ fraction of total labour income that is aggregate of skilled labour income and unskilled labour income is spent on the total value produced by sector Y. It is assumed that $r$ is Central Bank's policy instrument that is determined exogenously. The endogenous variables are $W_{S^{\prime}} W, i, K_{P} X, Y, M, P_{\gamma} I$ and policy parameters are $\gamma_{1^{\prime}} \gamma_{2^{\prime}} P_{r}$. Since, there are three factor prices \& one endogenized price of sector $\mathrm{Y}$ and three price systems, the model does not possess decomposition property. From Eq.(6) and Eq. (7) we can solve for $W$ and $W_{S}$ as a function of $i$. From Eq. (8) we get $i$ as a function of $P_{\gamma}$. Eq.(9) solves for $M$ and Eq. (10)-(12) solves for $X$ and $Y$ as a function of $P_{\gamma}$. In Eq.(13) we are left with one equation with one unknown $P_{\gamma}$. Thus, Eq. (9) by equating demand and supply we solve for $P_{\gamma}$. Eq. (11) solves for $K_{F}$. Conditions (B.a) and $(B . b)$ implies the assumption that sector $X$ is formal credit intensive relative to labour and labour intensive relative to informal credit respectively 
compared to sector $Y^{12}$. The model is stable in the sense that Walrasian stability is satisfied ${ }^{13}$. This completes the determination of the model.

\section{Measurement of Growth and Development}

Recent economic theory marks development distinct from traditional growth measures. In our paper we measure developmental implication for changes in policy parameters by constructing four indices, namely, wage inequality index $\left(I_{I N Q}\right)$, credit market exploitation index $(E)$, Gini Indix $(G)$ and workers welfare index $\left(H_{W}\right)^{14}$.

\section{COMPARATIVE STATIC EXERCISES}

In this section, we carry out a couple of comparative statics exercises ${ }^{14}$ pertaining to our analysis of few selected policies recently adopted by the Government as set goals delivered to curb the backwardness of Indian agriculture.

\section{Input Subsidy schemes}

After recent policy debates on the efficiency of Farm loan waiver schemes, it has been argued that input subsidy reforms either directly in terms of credit subsidy such as Interest Subvention Scheme or indirectly as subsidy in the purchase price of fertilizers or seeds are more efficient and sustaining measures. However, the debate averts from an important policy issue that is whether credit subsidy is to be provided to the small nontraded agriculture sector or large export intensive agriculture, this crucially turns upside down the expected predictions.

Let us first consider targeted input subsidy to the small non-traded agriculture. This implies a rise in $\gamma_{2}$ and hence associated fall in the cost of formal credit in sector $Y$. Thus, for given price $P_{Y}$ sector $Y$ demands more informal credit and labour that is released by sector $X$. Given factor intensity, sector $Y^{\prime}$ s demand for labour (informal credit) is proportionately lower (higher) than sector $X^{\prime}$ 's release of labour (informal credit) thus there exist excess labour (deficit of informal credit) requiring a fall (rise) in wage rate $W$ (informal interest $i$ ). Sector

\footnotetext{
${ }^{12}$ The factor-intensity conditions can be jointly expressed as $\frac{\theta_{F X}}{\theta_{F Y}}>\frac{\theta_{L X}}{\theta_{L Y}}>\frac{\theta_{I X}}{\theta_{I Y}}$

${ }^{13}$ See Appendix (E) for the mathematical derivation of stability of the model.

${ }^{14}$ See Appendix for detailed mathematical derivation.
}

$Y$ thus expands and given demand, price $P_{\gamma}$ falls. Following Stolper-Samuelson(SS) theorem $i$ falls and $W$ rises. Thus, there are two effects on $i$, first, $i$ rises due to direct fall in $\gamma_{2}$ effect and second $i$ falls due to price effect. If the direct lower cost effect dominates the price effect then informal interest rate $i$ rises and hence $W$ falls. In manufacturing sector (sector $\mathrm{M}$ ) to maintain zero profit $W_{S}$ falls. However, output in sector $M$ does not changes since it is already determined from its specific factor input of skilled labour endowment. The following proposition is immediate.

Proposition 1: A specific credit subsidy given to the non-traded agriculture sector leads to an expansion of the non-traded agriculture output and contraction of the exportable agriculture output, and depresses wage rate of either type of labour.

Proposition 2: Specific credit subsidy worsens wage inequality between skilled and unskilled workers, raises credit market exploitation and worsens aggregate workers' welfare.

Now, consider a uniform rate of subsidy to both the traded agriculture sector $X$ and non-traded agriculture sector $Y$. This is implied by $\hat{\gamma}_{1}=\hat{\gamma}_{2}=\hat{\gamma}>0$. Following the same logic and working principle of the model under the given set of factor intensities condition we have the following result.

$$
\left\{\begin{array}{c}
\hat{P}_{Y}>0 \\
\hat{\imath}<0 \text { if }\left|\left(\theta_{L X} \theta_{F Y}-\theta_{L Y} \theta_{F X}\right) \hat{\gamma}\right|>\left|\widehat{P}_{Y}\right| \\
\hat{Y}<0, \hat{X}>0 \\
\widehat{W}>0, \widehat{W}_{S}>0
\end{array}\right.
$$

Proposition 3: A uniform subsidy rate to both traded and non-traded agriculture sector leads to expansion of the traded agriculture sector at the cost to non-traded local output producing agriculture sector. Labour gains in terms of higher wage rate.

Proposition 4: Uniform subsidy rate leads to lower wage inequality, lower credit market exploitation and improved workers' welfare.

\section{Loan Waiver Schemes}

Governments usually resort to loan waiver schemes as a last response to farmers' resentment due to the neglect of the agriculture sector. Such schemes lead to issues related to moral hazard whereby 
productive farmers deliberately default their loan. Also, farmers producing local non-traded agricultural output prefer to raise consumption from money saved from loan waiver instead of investing it in farm activities. Thus the rate of loan default spikes up further. In our model, it is implied by $\hat{P}_{r}>0$. The following effects are obtained for the variables.

$$
\left\{\begin{array}{c}
\hat{P}_{Y}>0 \\
\hat{\imath}>0 \\
\widehat{W}<0, \quad \widehat{W}_{S}<0 \\
\hat{Y}<0 \text { if } \xi_{I i}|\hat{\imath}|<\xi_{I P_{r}}\left|\widehat{P}_{r}\right| \\
\hat{X}>0
\end{array}\right.
$$

Proposition 5: A loan waiver policy is not beneficial for the non-traded agriculture sector if the moneylender's sensitiveness (averseness) to the risk of loan default is relatively higher than its sensitiveness to informal interest rate, however, it is beneficial to the traded agriculture sector. Also, workers unambiguously loose in terms of lower wage rate.

Proposition 6: Loan waivers policy worsens wage inequality ${ }^{15}$, escalates credit market exploitation rate and deteriorate workers welfare.

\section{CONCLUSION AND \\ RECOMMENDATIONS}

The paper attempted to develop a theoretical understanding of some recent policy issues pertaining to the agriculture sector that presents crucial tradeoffs between growth and development, and also unveils that policies like targeted credit subsidy schemes or the loan waiver policy may produce counterproductive outcomes that have a conditional-conditioning relationship with an antiquated structure. Towards this, the paper developed a three sector General Equilibrium model in presence of credit market dualism. The paper obtained that a targeted credit subsidy policy accentuates aggregate real output growth rate of the non-traded backward agriculture, however, at the cost to development indicators. It leads to worsening of workers' welfare index, aggravates credit market

\footnotetext{
${ }^{15}$ Wage inequality worsens provided the sufficient condition $\frac{\theta_{I X}}{\theta_{L X}}>\frac{\theta_{I M}}{\theta_{S M}}$, it implies that value of expenditure share on skilled labour (informal credit) in sector $M$ is relatively higher (lower) than sector $X$.
}

exploitation rate and depresses wage rate of both skilled and unskilled workers. On the other hand, it is also obtained that a loan waiver policy may not be the panacea for agriculture distress. A loan waiver policy in the model is reflected as a rise in loan default rate due to moral hazard effect and the following counterproductive results were obtained. First, if the agrarian sector is characterized such as the export-intensive agriculture is endowed with a relatively larger share of the labour force compared to the share of informal credit than the local non-traded agriculture, then it would reduce aggregate agricultural output of the nontraded agriculture sector and would lead to an expansion of the traded agriculture sector output. Second, the aggregate workers' welfare worsens. Third, it leads to an escalation of the credit market exploitation index thus widening the gap between the informal interest rate and formal interest rate. These counterproductive outcomes are observed in the model because of the presence of the informal moneylender in the system that necessitates a proper evaluation of cost-benefit analysis before implementing such policies. As an alternative, it is very much evident from the model that a uniform credit subsidy policy produces more desirable outcomes. Also other policy measures such as developing agriculture infrastructure, spreading modern and scientific agriculture literacy, development of e-mandis (markets) can serve as an alternative to the archaic policy measures.

\section{REFERENCES}

Agricultural Statistics at a Glance. Directorate of Economics and Statistics, Ministry of Agriculture and Farmers Welfare, Government of India, 2016.

Banerjee, Rakhi, and Ranjanendra Narayan Nag. 2015. "Formal-Informal Credit Market Interlinkage and Development Policies: A General Equilibrium Analysis." Modern Economy, 6: 908-923.

Basu, Kaushik. 1998. "Rural Credit Markets." In Analytical Development Economics: The Less Developed Economy Revisited. Oxford India, 1998.

Chaudhuri, Sarbajit. 1999. "A Theory of Two-Tier Interlinkage in the Agricultural Credit Market: Comments." Keio Economic Studies, 36: 1999: 99-109.

Chaudhuri, Sarbajit. 2001. "Interaction of Formal and Informal Credit Markets in Backward Agriculture: A Theoretical Analysis." Indian Economic Review, New Series, 36(2): 411-428. 
Chaudhuri, Sarbajit. 1996. "Price Uncertainty and CreditProduct Interlinkage: A Note." Keio Economic Studies, 33(2): 103-115.

Chaudhuri, Sarbajit, and Krishnendu Ghosh Dastidar. 2011. "Corruption in a model of vertical linkage between formal and informal credit sources and credit subsidy policy." Economic Modelling, 28: 2596-2599.

Economic Survey 2017-18, Volume II. Department of Economic Affairs, Ministry of Finance, Government of India, 2018.

Ecoomic Survey 2015-16, Volume II. Department of Economic Affairs, Ministry of Finance, Government of India, 2016.

Gupta, Manash Ranjan. 1994. “Immigration in Less Developed Countries: A Theoretical Note." Journal of Economic Integration, 9(3): 416-425.

Gupta, Manash Ranjan, and Sarbajit Chaudhuri. 1997. "Formal Credit, Corruption and the Informal Credit Market in Agriculture: A Theoretical Analysis." Economica, 64: 331-343.
Jones, Ronald W. 1971. "A three-factor model in theory, trade and history", in Bhagwati, J.N. et al. eds., Trade, Balance of Payments and Growth, North-Holland Publishing Company.

Jones, Ronald W. 1965. "The Struture of Simple General Equilibrium Models." The Journal of Political Economy, 73(6): 557-572.

Jones, Ronald W, and Peter J. Neary. 1984. "Positive Theory of International Trade." In Handbook of Development Economics, Vol. 1, by Ronald W Jones and Peter Bain Kenen. North-Holland, Amsterdam.

Marjit, Sugata, Saibal Kar, and Rajat Acharyya. 2007. "Agricultural prospects and informal wage in general equilibrium." Economic Modelling, 24: 380-385.

Ray, Debraj. 1998. Development Economics. Princeton University Press.

Sen, A.K. 1974. "Informal Bases of Alternative Welfare Approaches: Aggregation and Income Distribution." Journal of Public Economics, 4. 


\section{APPENDIX}

\section{A. Derivation of informal credit supply function}

$$
\begin{gathered}
U=f(T, N) ; \quad f_{T}>0, f_{N}>0 \\
I=\bar{W}-N \\
T=(1+\bar{r}) N+(1+i)\left(1-P_{r}\right)(\bar{W}-N) \\
\\
\operatorname{Max} \quad U=f(T, N) \\
T, N \quad(1+\bar{r}) N+(1+i)\left(1-P_{r}\right)(\bar{W}-N)
\end{gathered}
$$

Now setting up Lagrangian in the constrained maximization process,

$$
L=f(T, N)+\lambda\left\{T-(1+\bar{r}) N-(1+i)\left(1-P_{r}\right)(\bar{W}-N)\right\}
$$

The first order conditions (F.O.C's) are,

$$
\begin{gathered}
\frac{\delta L}{\delta T}=f_{T}+\lambda=0 \\
\frac{\delta L}{\delta N}=f_{N}+\lambda\left\{-(1+\bar{r})+(1+i)\left(1-P_{r}\right)\right\}=0 \\
\frac{\delta L}{\delta \lambda}=T-(1+\bar{r}) N-(1+i)\left(1-P_{r}\right)(\bar{W}-N)=0
\end{gathered}
$$

Dividing equation (A.5.2) by equation (A.5.1) we get,

$$
\frac{f_{N}}{f_{T}}=(1+i)\left(1-P_{r}\right)-(1+\bar{r})
$$


Solving F.O.C's and equation (A.2) we derived the informal credit supply function as,

$$
I=I\left(\begin{array}{ccc}
P_{r} & i & \bar{r} \\
(-) & (+) & (-)
\end{array}\right)
$$

\section{B. Equations of Change}

\section{$\underline{\text { General condition }}$}

Factor intensity using Jones (1965)

$$
\begin{aligned}
& \frac{\lambda_{L X}}{\lambda_{I X}}>\frac{\lambda_{L Y}}{\lambda_{I Y}} \text { or } \frac{\theta_{L X}}{\theta_{I X}}>\frac{\theta_{L Y}}{\theta_{I Y}} \quad(B . a) \\
& \frac{\lambda_{F X}}{\lambda_{L X}}>\frac{\lambda_{F Y}}{\lambda_{L Y}} \text { or } \frac{\theta_{F X}}{\theta_{L X}}>\frac{\theta_{F Y}}{\theta_{L Y}} \quad(B . b)
\end{aligned}
$$

Totally differentiating equation (6) we get,

$$
\begin{aligned}
& \frac{W_{S} a_{S M}}{P_{M}^{*}} \frac{d W_{S}}{W_{S}}+\frac{i a_{I M}}{P_{M}^{*}} \frac{d i}{i}=0 \\
& \theta_{S M} \widehat{W}_{S}+\theta_{I M} \hat{\imath}=0
\end{aligned}
$$

Similarly totally differentiating equation (7) and equation (8) respectively we get,

$$
\begin{gathered}
\theta_{L X} \widehat{W}-\theta_{F X} \gamma_{1} \widehat{\gamma_{1}}+\theta_{I X} \hat{\imath}=0 \\
\theta_{L Y} \widehat{W}-\theta_{F Y} \gamma_{2} \widehat{\gamma_{2}}+\theta_{I Y} \hat{\imath}=\widehat{P_{Y}}
\end{gathered}
$$

Totally differentiating equation (9) to equation (11) respectively we get,

$$
\begin{aligned}
& \widehat{M}=0 \\
& \lambda_{L X} \hat{X}+\lambda_{L Y} \hat{Y}=0
\end{aligned}
$$




$$
\begin{gathered}
\hat{X}=-\frac{\lambda_{L Y}}{\lambda_{L X}} \hat{Y} \\
\lambda_{F X} \hat{X}+\lambda_{F Y} \hat{Y}=\vartheta \widehat{\bar{F}}+(1-\vartheta) \widehat{K_{F}}, \text { where } \vartheta=\frac{\bar{F}}{\bar{F}+K_{F}} \\
\lambda_{I X} \hat{X}+\lambda_{I Y} \hat{Y}=\varepsilon_{I i} \hat{\imath}+\varepsilon_{I P_{r}} \widehat{P}_{r} \\
\text { where } \varepsilon_{I j}=\frac{\delta I\left(i, P_{r}\right)}{\delta j} \frac{j}{I\left(i, P_{r}\right)} \text {, for } j=\left\{i, P_{r}\right\} \& \varepsilon_{I i}>0, \varepsilon_{I P_{r}}<0
\end{gathered}
$$

here, $\varepsilon_{I j}=$ elasicity of informal credit supply with respect to variable $j$

$$
\beta \widehat{W_{S}}+(1-\beta) \widehat{W}=\widehat{Y}+\widehat{P_{Y}}, \text { where } \beta=\frac{\alpha W_{S} \bar{S}}{P_{Y} Y} \quad \& 0<\beta<1
$$

From (B.1) we get,

$$
\widehat{W_{S}}=-\frac{\theta_{I M}}{\theta_{S M}} \hat{\imath}
$$

From (B.2) we get,

$$
\widehat{W}=\frac{\theta_{F X}}{\theta_{L X}} \gamma_{1} \widehat{\gamma_{1}}-\frac{\theta_{I X}}{\theta_{L X}} \hat{\imath}
$$

From (B.3) we get,

$\hat{\imath}=\left(\frac{\theta_{L X}}{\theta_{L X} \theta_{I Y}-\theta_{L Y} \theta_{I X}}\right) \widehat{P_{Y}}+\frac{A}{\left(\theta_{L X} \theta_{I Y}-\theta_{L Y} \theta_{I X}\right)}$, where $A=\theta_{L X} \theta_{F Y} \gamma_{2} \widehat{\gamma_{2}}-\theta_{L Y} \theta_{F X} \gamma_{1} \widehat{\gamma_{1}}$

From (B.5) we get,

$$
\hat{X}=-\frac{\lambda_{L Y}}{\lambda_{L X}} \hat{Y}
$$


From (B.7) we get,

$$
\hat{Y}=\frac{\left(\varepsilon_{I i} \hat{\imath}+\varepsilon_{I P_{r}} \widehat{P}_{r}\right) \lambda_{L X}}{\left(\lambda_{L X} \lambda_{I Y}-\lambda_{I X} \lambda_{L Y}\right)}
$$

From (B.8)

$$
(1-\beta) \frac{\theta_{F X}}{\theta_{L X}} \gamma_{1} \widehat{\gamma_{1}}-B-\frac{A C}{\left(\theta_{L X} \theta_{I Y}-\theta_{L Y} \theta_{I X}\right)}=\widehat{P_{Y}}\left\{1+\frac{\theta_{L X} C}{\left(\theta_{L X} \theta_{I Y}-\theta_{L Y} \theta_{I X}\right)}\right\}
$$

where $B=\frac{\varepsilon_{I P_{r}} \widehat{P}_{r} \lambda_{L X}}{\left(\lambda_{L X} \lambda_{I Y}-\lambda_{I X} \lambda_{L Y}\right)}$ and $C=\left\{\frac{\varepsilon_{I I} \lambda_{L X}}{\left(\lambda_{L X} \lambda_{I Y}-\lambda_{I X} \lambda_{L Y}\right)}+\frac{\beta \theta_{I M}}{\theta_{S M}}+(1-\beta) \frac{\theta_{I X}}{\theta_{L X}}\right\}$

From (B.6)

$$
\widehat{K_{F}}=\frac{\hat{Y}\left\{\frac{\left(\lambda_{L X} \lambda_{F Y}-\lambda_{F X} \lambda_{L Y}\right)}{\lambda_{L X}}\right\}-\vartheta \widehat{\bar{F}}}{(1-\vartheta)}
$$

\section{Measures of Growth and Development}

\section{C.1. Wage Inequality Index}

The wage inequality is given by the relative skilled-unskilled wage ratio i.e.

$$
\frac{W_{S}}{W}=i_{I N Q}
$$

Taking $\log$ on both sides and totally differentiation we get,

$$
\begin{aligned}
& I_{I N Q} \equiv \iota_{I N Q}=\widehat{W_{S}}-\widehat{W} \\
& \text { If } \left.\begin{array}{c}
I_{I N Q}>0 \text { then income inequality increases } \\
I_{I N Q}<0 \text { then income inequality decreases }
\end{array}\right\}
\end{aligned}
$$




\section{C.2. Gini Index}

Let, there are $m$ distinct incomes in the economy and in each income class $j$, the number of individuals earning that income is denoted by $n_{j}$. So, total number of individual is given by, $n=\sum_{j=1}^{m} n_{j}$. Then $\mu$ (the average income)is

$$
\mu=\frac{1}{n} \sum_{j=1}^{m} n_{j} y_{j}, \text { where } y_{\mathrm{j}} \text { is the income earned by } j \text { th income group }
$$

So, the Gini Index is defined as,

$$
G=\frac{1}{2 n^{2} \mu} \sum_{j=1}^{m} \sum_{k=1}^{m} n_{j} n_{k}\left|y_{j}-y_{k}\right|, 0<G<1
$$

In our model,

$m=2, \quad n_{j}=$ number of skilled labour, $\quad n_{k}=$ number of unskilled labour

$$
y_{j}=W_{S}, \quad y_{k}=W, \quad n=\bar{S}+\bar{L}, \quad \mu=\frac{W_{S} \bar{S}+W \bar{L}}{(\bar{S}+\bar{L})}
$$

So, in our model $G$ takes the form,

$$
G=\frac{\bar{S} \bar{L}\left|W_{S}-W\right|}{(\bar{S}+\bar{L})\left(W_{S} \bar{S}+W \bar{L}\right)}
$$




\section{C.3. Workers' Welfare Index}

The workers' welfare index (Sen, 1974) is given by,

$$
H_{w}=n \mu(1-G)
$$

Substituting the values for $n, \mu$ and $G$

$$
\begin{aligned}
& H_{w}=(\bar{S}+\bar{L})\left(\frac{W_{S} \bar{S}+W \bar{L}}{\bar{S}+\bar{L}}\right)\left\{1-\frac{\bar{S} \bar{L}\left|W_{S}-W\right|}{(\bar{S}+\bar{L})\left(W_{S} \bar{S}+W \bar{L}\right)}\right\} \\
& H_{w}=\left(W_{S} \bar{S}+W \bar{L}\right)-\left\{\frac{\bar{S} \bar{L}\left|W_{S}-W\right|}{(\bar{S}+\bar{L})}\right\}
\end{aligned}
$$

Taking total differential we get,

$$
\begin{array}{r}
H_{w} \widehat{H}_{w}=\left(\widehat{W}_{S} W_{S} \bar{S}\right)\left\{1-\frac{\bar{L}}{(\bar{S}+\bar{L})}\right\}+(\widehat{W} W \bar{L})\left\{1+\frac{\bar{S}}{(\bar{S}+\bar{L})}\right\} \\
\text { Where }\left\{1-\frac{\bar{L}}{(\bar{S}+\bar{L})}\right\}>0 \text { and }\left\{1+\frac{\bar{S}}{(\bar{S}+\bar{L})}\right\}>0
\end{array}
$$

\section{C.4. Credit Market Exploitation}

It is given by the relative ratio of informal interest rate to formal interest rate i.e.

$$
\frac{i}{\bar{r}}=e
$$

Taking log on both sides and totally differentiating we get,

$$
\left.E \equiv \hat{e}=\hat{\imath}, \text { If } \begin{array}{c}
E>0 \text { means credit exploitation rate increases } \\
E<0 \text { means credit exploitation rate decreases }
\end{array}\right\}
$$




\section{Comparative static results}

D.1. $\left(\widehat{\gamma_{2}}>0\right)$

From equation (B.8.1) we get $\widehat{P_{Y}}<0$. From equatio (B.3.1) we get $\hat{\imath}>0$ if $\left|\theta_{F Y} \widehat{\gamma_{2}} \widehat{\gamma_{2}}\right|>$ $\left|\widehat{P_{Y}}\right|$. From equation (B.7.1), (B.5.1), (B.2.1) and (B.1.1) we get $\widehat{Y}>0, \hat{X}<0, \widehat{W}<$ 0 and $\widehat{W}_{S}<0$ respectively. Then from equation (B.6.1) we get $\widehat{K_{F}}<0$.

Now, on the basis of these results we can find out the effects on development indices.

From equation (C.1.1) we can say that $I_{I N Q}$ is ambiguous.

From equation (C.3.1.3) we get that $\widehat{H_{w}}<0$.

From equation (C.4.1) it is evident that $E>0$.

D.2 $\cdot\left(\widehat{\gamma_{1}}=\widehat{\gamma_{2}}>0\right)$

By the similar process (discussed in D.1) it is determined that, $\widehat{P_{Y}}>0, \hat{\imath}<0$ iff $|A|>\left|\widehat{P_{Y}}\right|, \hat{Y}<0, \widehat{X}>0, \widehat{W}>0$ and $\widehat{W_{S}}>0, \widehat{K_{F}}>0$ $I_{I N Q}$ is ambiguous, $\widehat{H_{w}}>0, E<0$

D.3. $\left(\widehat{\boldsymbol{P}_{\boldsymbol{r}}}>0\right)$

By the similar process (discussed in D.1) it is determined that, $\widehat{P_{Y}}>0, \hat{\imath}>0, \hat{Y}>0$ iff $\varepsilon_{I i}|\hat{\imath}|>\varepsilon_{I P_{r}}\left|\widehat{P}_{r}\right|, \widehat{X}<0, \widehat{W}<0$ and $\widehat{W_{S}}<0, \widehat{K_{F}}<0$, $I_{I N Q}>0$ if $\frac{\theta_{\mathrm{IX}}}{\theta_{\mathrm{LX}}}>\frac{\theta_{\mathrm{IM}}}{\theta_{\mathrm{SM}}} ; \quad \widehat{H_{w}}<0, \quad E>0$

\section{E. Derivation of stability condition}

Excess Demand is defined as,

$$
E D=\frac{\alpha\left(W_{S} \bar{S}+W \bar{L}\right)}{P_{Y}}-Y
$$


For stability we require $\frac{\delta E D}{\delta P_{Y}}<0$

Proof:-

Differentiating both sides of (E.1) by $P_{Y}$ we get,

$$
\begin{aligned}
& \frac{\delta E D}{\delta P_{Y}}=\frac{P_{Y}\left\{\alpha\left(\bar{S} \frac{\delta W_{S}}{\delta P_{Y}}+\bar{L} \frac{\delta W}{\delta P_{Y}}\right)\right\}-\alpha\left(W_{S} \bar{S}+W \bar{L}\right)}{P_{Y}{ }^{2}}-\frac{\delta Y}{\delta P_{Y}} \\
& =>\frac{\alpha}{P_{Y}{ }^{2}}\left(\frac{\widehat{W_{S}} \bar{S} W_{S}}{\widehat{P_{Y}}}+\frac{\widehat{W} \bar{L} W}{\widehat{P_{Y}}}\right)-\frac{\alpha}{{P_{Y}}^{2}}\left(W_{S} \bar{S}+W \bar{L}\right)-\frac{\widehat{Y} Y}{\widehat{P_{Y} P_{Y}}}
\end{aligned}
$$

Substituting the values for $\widehat{W}_{S}$ and $\widehat{W}$, we get,

$$
=>\frac{Y}{P_{Y} \widehat{P_{Y}}}\left\{\frac{-\beta \theta_{I M}}{\theta_{S M}} \hat{\imath}-\frac{(1-\beta) \theta_{L X}}{\theta_{L X}} \hat{\imath}-\hat{Y}\right\}-\frac{Y}{P_{Y}}
$$

Substituting $\hat{\imath}$ the expression finally boils down to,

$$
\frac{\delta E D}{\delta P_{Y}}=-\frac{Y}{P_{Y}}\left[\frac{1}{\left(\theta_{L X} \theta_{I Y}-\theta_{L Y} \theta_{I X}\right)}\left\{\frac{\beta \theta_{I M} \theta_{L X}}{\theta_{S M}}+(1-\beta) \theta_{I X}+\frac{\lambda_{L X} \theta_{L X} \varepsilon_{I i}}{\left(\lambda_{L X} \lambda_{I Y}-\lambda_{I X} \lambda_{L Y}\right)}\right\}+1\right]
$$

Given the factor intensity conditions (B.a. and B.b.), Walrasian stability condition is satisfied

$$
\text { i.e. } \frac{\delta E D}{\delta P_{Y}}<0 \text {. }
$$


